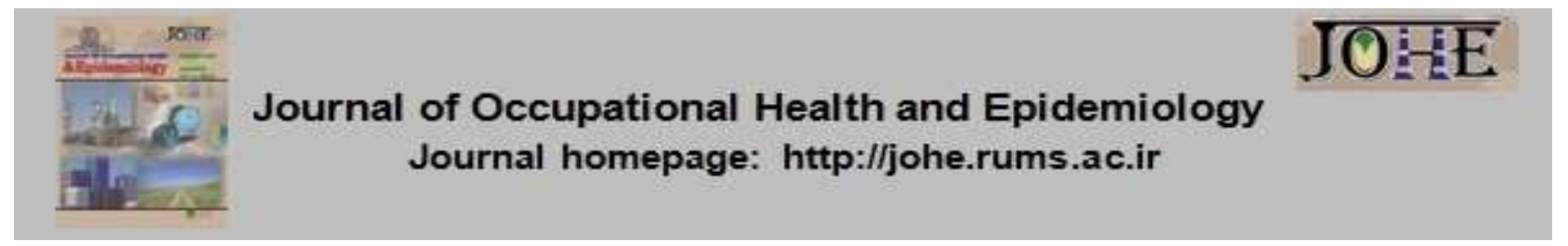

\title{
Prevalence of low back pain and its associated factors among physiotherapists in Dhaka city of Bangladesh in 2016
}

\author{
Rajib Mondal ${ }^{1 *}$, Rajib Chandra Sarker ${ }^{1}$, Sumi Akter ${ }^{2}$, Palash Chandra Banik ${ }^{1}$, Simson Kalyan Baroi ${ }^{3}$ \\ 1- Department of Noncommunicable Diseases, Bangladesh University of Health Sciences (BUHS), Dhaka, Bangladesh. \\ 2- Department of Physiotherapy, Institute of Health Technology (IHT), Dhaka, Bangladesh \\ 3- Physiotherapy and Paralysed Welfare Centre (PPWC), Dhaka, Bangladesh
}

\section{Article Info}

${ }^{*}$ Corresponding authors:

Rajib Mondal,

E-mail:

rajibmondaluday@gmail.com

\section{Article history}

Received: Feb, 2017

Accepted: May, 2018

10.29252/johe.7.2.70

Print ISSN: 2251-8096 Online ISSN: 2252-0902

Peer review under responsibility of Journal of Occupational Health and Epidemiology
Citation: Mondal R, Saker RCh, Akter S, Banik PCh, Baroi SK. Prevalence of low back pain and its associated factors among physiotherapists in Dhaka city of Bangladesh in 2016. JOHE. 2018; 7(2):70-4.

\begin{abstract}
Background: Low back pain (LBP) is one of the major public health issues among health care professionals, especially among the physiotherapists. The aim of this study was to determine the prevalence of LBP among Bangladeshi physiotherapists and its associated factors.

Materials and Methods: A cross-sectional study was conducted among 130 physiotherapists practicing in Dhaka city. Hospitals, clinics and private chambers, and the respondents were selected conveniently (on invitation those who were agreed to participate). Verbal rating score was used to evaluate the severity of pain where the respondents also asked the necessary questions. Face-to-face interviews were conducted using a researcher-administered structured questionnaire. Both descriptive and comparative (chi-square test and binary logistic regression analysis) statistics were done using SPSS software.

Results: Men respondents were dominator [n: 85 (65.4\%)], and the mean \pm standard deviation of age and body mass index (BMI) of all of the respondents were $31.1 \pm 7.1$ years and $23.5 \pm 2.9 \mathrm{~kg} / \mathrm{m}^{2}$, respectively. Study found three in every five [n: $79(60.8 \%)$; $95 \%$ of confidence interval $(\mathrm{Cl}): 52.4-69.2]$ physiotherapists suffered from LBP. Lack of maintenance of correct posture, most frequent posture during practice and absence of lumber support on chair were found significantly associated factors with LBP among physiotherapists.

Conclusion: Current study clearly revealed a higher proportion of Bangladeshi physiotherapists were suffering from LBP, which was associated with lack of maintenance of correct posture, most frequent postures during practice and absence of lumber support on chair.
\end{abstract}

Keywords: Low Back Pain, Physiotherapists, Bangladesh, Musculoskeletal disorders

\section{Introduction}

Low back pain (LBP) is a common phenomenon among certain type of professionals (1-4) along with health care professionals. Such as doctors, nurses $(1,5,6)$, and even physiotherapists (7-10) are also within the paw of LBP. When an individual needs to maintain same postures for over period of time and/or bending and twisting movements, it causes excesses tension over the particular parts of body, and creates repetitive injuries to the joints, ligaments, muscles, nerves, tendons, etc., and ultimately leads to work-related chronic LBP (11). Likely this mechanism, physiotherapists are at constantly high risk to develop LBP due to their stressful body positions involving frequently standing, bending, and lifting to achieve effective functional positions to treat their patients (7). 
Among all kinds of bodily pains, LBP is very common worldwide, and it is the most disabling factor in workplace. It was reported that, over $80 \%$ of world population affected by LBP in their lifetime (12), and in $37 \%$ of cases, LBP was attributed by their occupations, whereas men were affected more due to higher involvement with heavy lifting work (13). LBP is responsible for high treatment costs, frequent sick leave, prolonged episode of back pain, sometime job loss, burden over family, etc., which may lead to further psychological problems like depression (13-15).

Worldwide, reports stated that around $60 \%$ of health care professionals were suffered by LBP within last 1 year, and $65 \%-84 \%$ suffered anytime during their lifetime $(1,5,6)$. Particularly among the physiotherapists, the prevalence of LBP was reported $32 \%-72 \%$ (7-10). Moreover, the factors sex, age, physiotherapist's rank and specialty, duration of patient handling, uncomfortable position, prolonged standing, bending, and twisting were found significantly related to LBP (7-9). But there was no such kind of data among Bangladeshi physiotherapists revealing the proportion of LBP. Therefore, the current study was conducted to explore the prevalence of LBP among Bangladeshi physiotherapists along with associated factors maintaining appropriate ethical consideration.

\section{Materials and Methods}

It was a cross-sectional study conducted in 2016 among 130 physiotherapists practicing in few conveniently selected hospitals, clinics, and private chambers in Dhaka City. Total 145 physiotherapists in the selected study settings those who had at least Diploma degree were recognized as study population. However, 130 physiotherapists were reached according to their convenience; those who were the final respondents of the study. A structured questionnaire was developed which covered sociodemographic characteristics such as age, sex, education, marital status, and monthly income, anthropometric measurements such as height and weight, practice-related, and LBP-related characteristics. Face-to-face interviews were conducted for data collection. Verbal rating scale (VRS) rated 0 to 10 was used to evaluate the severity of pain based on respondent's own pain perception and recorded as mild, moderate, and severe when self-reported scores were 1-3, 4-6, and 7-10, respectively (16).

Body mass index (BMI) was calculated following the World Health Organization (WHO) standard formula (17) using respondent's self-reported weight and height. And, the respondents were identified as underweight, normal weight, overweight, and obese based on their BMl when $<17.5, \quad 17.5-22.9,23.0-27.9$, and $\geq 28.0 \mathrm{~kg} / \mathrm{m}^{2}$, respectively, also following WHO BMI criteria for Asian people (17).

After collection of all data, these were checked and rechecked for completeness and internal consistency. After discarding the incomplete and inconsistent data, the final data were entered into the SPSS software (version 20, IBM Corporation, Armonk, NY, USA), and analyzed.

Descriptive statistics were done for univariate data expressing as mean, standard deviation (SD), and percentage, and comparative statistics such as Chi-square test and binary logistic regression analysis were performed to see the associated factors as well as independent predictors related to LBP. Statistical significance was considered when $p$-value was less than 0.05 . Both verbal and written inform consents were taken from the respondents prior to data collection, and other ethical issues were maintained strictly.

\section{Results}

Men respondents were dominator (65\%), and the mean \pm SD of age of all of the respondents was $31.1 \pm 7.1$ years (men, $32.3 \pm 7.9$ and women, 29.1 \pm 4.8 years). Most of them were Bachelor degree holders (85\%) and married (61\%). The mean \pm SD of BMl and monthly household income of them were $23.5 \pm 2.9 \mathrm{~kg} / \mathrm{m}^{2}$ and $37,678 \pm 33,726$ Bangladeshi Taka (BDT) (approximately 80 BDT = 1 USD), respectively (Table 1 ).

Almost half of the respondents (48\%) were involved in physiotherapy practice for less than five years, more than half $(56 \%)$ were used to work for 6-8 hours daily, seven in ten individuals (69\%) maintained correct posture, and most of them (67\%) were used to practice physiotherapy on standing position. However, almost eight in ten individuals $(79 \%)$ did not have lumber supports on their chair, and a noticeable proportion (43\%) was used to feel mental stress on their practices. More than one-third of them $(37 \%)$ were engaged in regular physical exercise, and only $30 \%$ were used to perform regular back strengthening exercise (Table 2).

Current study found a large proportion of physiotherapists in Bangladesh was suffering from low back pain, whereas three in every five [n: 79 (60.8\%); 95\% Cl:52.4-69.2] were affected. The median duration of pain was found 2 months, although most of them had mild pain (57.0\%).

Mainly, standing and bending both postures were used to cause worsen of their pain (36.7\%). 
Because of pain, most of the affected respondent's were mildly for majority (66.0\%) of them.

$(63.3 \%)$ practices were hampered, although these

Table 1: Distribution of socio-demographic factors and their relationship with low back pain among the physiotherapists of Dhaka City, Bangladesh, in $2016(n=130)$

\begin{tabular}{|c|c|c|c|c|c|c|}
\hline \multirow{2}{*}{\multicolumn{2}{|c|}{ Variables }} & \multirow{4}{*}{$\begin{array}{c}\mathbf{N}(\%) \\
85(65.4) \\
45(34.6)\end{array}$} & \multicolumn{2}{|c|}{ Low back pain (\%) } & \multirow{4}{*}{$\begin{array}{c}\begin{array}{c}\text { Chi- } \\
\text { square }\end{array} \\
0.390\end{array}$} & \multirow{4}{*}{$\frac{p \text { value }}{0.532}$} \\
\hline & & & Yes & No & & \\
\hline \multirow{2}{*}{ Sex } & Men & & 58.8 & 41.2 & & \\
\hline & Women & & 64.4 & 35.6 & & \\
\hline \multirow{4}{*}{ Age } & Below 30 years & $69(53.1)$ & 59.4 & 40.6 & \multirow{4}{*}{1.125} & \multirow{4}{*}{0.771} \\
\hline & $30-34$ years & $32(24.6)$ & 59.4 & 40.6 & & \\
\hline & $35-39$ years & $12(9.2)$ & 75.0 & 25.0 & & \\
\hline & 40 years and above & $17(13.1)$ & 58.8 & 41.2 & & \\
\hline \multirow{3}{*}{ Educational status } & Diploma in physiotherapy & $8(6.2)$ & 50.0 & 50.0 & \multirow{3}{*}{1.716} & \multirow{3}{*}{0.424} \\
\hline & Bachelor in physiotherapy & $111(85.4)$ & 63.1 & 36.9 & & \\
\hline & Masters in physiotherapy & $11(8.5)$ & 45.5 & 54.5 & & \\
\hline \multirow{2}{*}{ Marital status } & Unmarried & $51(39.2)$ & 66.7 & 33.3 & \multirow{2}{*}{1.224} & \multirow{2}{*}{0.269} \\
\hline & Married & $79(60.8)$ & 57.0 & 43.0 & & \\
\hline \multirow{4}{*}{ Body mass index } & Underweight & $2(1.5)$ & 50.0 & 50.0 & \multirow{4}{*}{1.918} & \multirow{4}{*}{0.590} \\
\hline & Normal weight & $57(43.8)$ & 56.1 & 43.9 & & \\
\hline & Over weight & $63(48.5)$ & 66.7 & 33.3 & & \\
\hline & Obese & $8(6.2)$ & 50.0 & 50.0 & & \\
\hline \multirow{3}{*}{$\begin{array}{l}\text { Monthly income } \\
\text { (BDT) }\end{array}$} & Up to 30000 & $79(60.8)$ & 60.8 & 39.2 & \multirow{3}{*}{2.158} & \multirow{3}{*}{0.340} \\
\hline & $30001-50000$ & $43(33.1)$ & 65.1 & 34.9 & & \\
\hline & More than 50000 & $8(6.2)$ & 37.5 & 62.5 & & \\
\hline
\end{tabular}

$p$ value obtained from Chi-square test.

LBP: low back pain; BDT: Bangladeshi Taka

Table 2: Distribution of work- and physical activity-related factors and their relationship with low back pain among the physiotherapists of Dhaka City, Bangladesh, in $2016(n=130)$

\begin{tabular}{|c|c|c|c|c|c|c|}
\hline \multirow{2}{*}{\multicolumn{2}{|c|}{ Variables }} & \multirow{2}{*}{$\mathbf{N}(\%)$} & \multicolumn{2}{|c|}{ Low back pain (\%) } & \multirow{2}{*}{ Chi-square } & \multirow{2}{*}{ p value } \\
\hline & & & Yes & No & & \\
\hline \multirow{3}{*}{ Job duration } & Less than 5 years & $62(47.7)$ & 59.7 & 40.3 & \multirow{3}{*}{4.336} & \multirow{3}{*}{0.114} \\
\hline & 5-10 years & $31(23.8)$ & 48.4 & 51.6 & & \\
\hline & More than 10 years & $37(28.5)$ & 73.0 & 27.0 & & \\
\hline \multirow{3}{*}{ Daily work duration } & Less than 6 hours & $14(10.8)$ & 57.1 & 42.9 & \multirow{3}{*}{2.187} & \multirow{3}{*}{0.335} \\
\hline & 6-8 hours & $73(56.2)$ & 56.2 & 43.8 & & \\
\hline & More than 8 hours & $43(33.1)$ & 69.8 & 30.2 & & \\
\hline \multirow{2}{*}{$\begin{array}{c}\text { Maintenance of correct } \\
\text { posture }\end{array}$} & Yes & $90(69.2)$ & 52.2 & 47.8 & \multirow{2}{*}{8.963} & \multirow{2}{*}{$0.003^{*}$} \\
\hline & No & $40(30.8)$ & 80.0 & 20.0 & & \\
\hline \multirow{3}{*}{$\begin{array}{l}\text { Most frequent postures } \\
\text { during practice }\end{array}$} & Sitting & $30(23.1)$ & 43.3 & 56.7 & \multirow{3}{*}{9.311} & \multirow{3}{*}{$0.010^{*}$} \\
\hline & Forward bending & $13(10.0)$ & 92.3 & 7.7 & & \\
\hline & Standing & $87(66.9)$ & 62.1 & 37.9 & & \\
\hline \multirow{2}{*}{ Lumber support on chair } & Yes & $27(20.8)$ & 37.0 & 63.0 & \multirow{2}{*}{8.051} & \multirow{2}{*}{$0.005^{\star}$} \\
\hline & No & $103(79.2)$ & 67.0 & 33.0 & & \\
\hline \multirow{2}{*}{$\begin{array}{c}\text { Feeling of mental stress } \\
\text { on practice }\end{array}$} & Yes & $56(43.1)$ & 76.8 & 23.2 & \multirow{2}{*}{10.586} & \multirow[b]{2}{*}{$0.001^{*}$} \\
\hline & No & $74(56.9)$ & 48.6 & 51.4 & & \\
\hline \multirow{2}{*}{ Regular physical exercise } & Yes & $48(36.9)$ & 54.2 & 45.8 & \multirow{2}{*}{1.392} & \multirow{2}{*}{0.238} \\
\hline & No & $82(63.1)$ & 64.6 & 35.4 & & \\
\hline \multirow{2}{*}{$\begin{array}{c}\text { Regular back } \\
\text { strengthening exercise }\end{array}$} & Yes & $39(30.0)$ & 59.0 & 41.0 & \multirow{2}{*}{0.075} & \multirow{2}{*}{0.784} \\
\hline & No & $91(70.0)$ & 61.5 & 38.5 & & \\
\hline
\end{tabular}

$p$ value obtained from Chi-square test.

*: significant relationship

Again, more than half of the affected respondents $(51.9 \%)$ had mild difficulties during performing their activities of daily living (ADL). Most of them were receiving treatment for their pain $(79.7 \%)$ which was physiotherapy mainly $(95.2 \%)$ in types of treatment (Table 3). 
Furthermore, this study did not find significant relationship between low back pain of physiotherapists and their socio-demographic factors (Table 1), but found with work-related factors like maintenance of correct posture $(p=$ $0.003)$, most frequent postures during practice $(p=$ $0.010)$, lumber support on chair $(p=0.005)$ as well as feeling of mental stress on practice $(p=0.001)$ (Table 2). Again, significant relationships were observed for maintenance of correct posture [odds ratio $(\mathrm{OR})=3.660 ; 95 \% \mathrm{Cl}: 1.521-8.807 ; \mathrm{p}=$ $0.004)$, lumber support on chair $(O R=3.450$; 95\%Cl: 1.427-8.338; $p=0.006)$, and feeling of mental stress on practice $(\mathrm{OR}=3.491 ; 95 \% \mathrm{Cl}$ : 1.617-7.539; $p=0.001$ ), reflecting as independent predictors related to LBP when binary logistic regression models were run.

Table 3: Distribution of low back pain related factors among the physiotherapists of Dhaka city in $2016(n=130)$

\begin{tabular}{|c|c|c|c|}
\hline \multicolumn{2}{|c|}{ Variables } & n (\%) & $\begin{array}{l}95 \% \text { confidence } \\
\text { interval }\end{array}$ \\
\hline \multirow{2}{*}{$\begin{array}{c}\text { Presence of low back pain }(n= \\
130)\end{array}$} & Yes & $79(60.8)$ & $52.4-69.2$ \\
\hline & No & $51(39.2)$ & $30.8-47.6$ \\
\hline Duration of pain $(n=79)$ & Median = 2 months & $14(10.8)$ & $5.5-16.1$ \\
\hline \multirow{3}{*}{$\begin{array}{l}\text { Self-reported severity of pain }(n= \\
79)\end{array}$} & Mild (Verbal Rating Score: 1-3) & $45(57.0)$ & $48.5-65.5$ \\
\hline & Moderate (Verbal Rating Score: 4-6) & $29(36.7)$ & $28.4-45.0$ \\
\hline & Severe (Verbal Rating Score: 7-10) & $5(6.3)$ & $2.1-10.5$ \\
\hline \multirow{5}{*}{$\begin{array}{l}\text { Postures used to cause worsening } \\
\text { of pain (MR, } n=79 \text { ) }\end{array}$} & Standing & $29(36.7)$ & $28.4-45.0$ \\
\hline & Sitting & $16(20.3)$ & $13.4-27.2$ \\
\hline & Lying & $3(3.8)$ & $0.5-7.1$ \\
\hline & Bending & $29(36.7)$ & $28.4-45.0$ \\
\hline & Walking & $4(5.1)$ & $1.3-8.9$ \\
\hline \multirow{2}{*}{ Practice hampered by pain $(n=79)$} & Yes & $50(63.3)$ & $55.0-71.6$ \\
\hline & No & $29(36.7)$ & $28.4-45.0$ \\
\hline \multirow{3}{*}{ Severity of hampering $(n=50)$} & Mild & $33(66.0)$ & $57.9-74.1$ \\
\hline & Moderate & $12(24.0)$ & $16.7-31.3$ \\
\hline & Severe & $5(10.0)$ & $4.8-15.2$ \\
\hline \multirow{3}{*}{ ADL affected by pain $(n=79)$} & Not at all & $31(39.2)$ & $30.8-47.6$ \\
\hline & Mild & $41(51.9)$ & $43.3-60.5$ \\
\hline & Moderate & $7(8.9)$ & $4.0-13.8$ \\
\hline
\end{tabular}

MR: Multiple responses were recorded; ADL: Activities of daily living

\section{Discussion}

Current study first explored the work-related LBP along with its associated factors among physiotherapists in Bangladesh. The study found a remarkable proportion of Bangladeshi physiotherapists $(60.8 \%)$ was suffering from LBP during the study time. This prevalence was noticeably higher than the study conducted in Saudi Arabia (35.6\%) (7). Possible reason of higher prevalence might be the higher year of professional experience among the physiotherapists of the present study. Again, another study from the same country (8) reported a higher prevalence of LBP (72\%) than current study. Possible reason might be the higher proportion of physiotherapy technicians occupied in that study, whereas, that study also revealed higher prevalence of LBP among the technicians. Around $57 \%$ of physiotherapists of Gaza Strip suffered from LBP (9), which revealed almost similar prevalence with current study. In addition, the prevalence was almost twice in the present study when compared to a relevant study from Kuwait (32\%) (10). The higher working hours in a day among the physiotherapists of current study than that of Kuwaiti study might be the possible reason of noticeably higher prevalence.

Although, more than three-quarter $(77.7 \%)$ of the respondents of this current study were below 35 years, yet it can be expressed that prevalence of LBP among Bangladeshi physiotherapists is more alarming than other advanced countries. Current study found maintenance of correct posture, most frequent postures during practice, lumber support on chair, and feeling of mental stress on practice were significantly associated with LBP among physiotherapists; whereas sex, physiotherapist's specialty, duration of contact with patients as well as maintenance of postures were found significantly related by other studies (7-9).

Comparatively, less proportion of women physiotherapists as well as large proportion of very young physiotherapists, those who had practice experience less than 5 years, were occupied in this 
study that might cause potential effects on prevalence sought for. Further studies are needed to design in order to insight more clear picture regarding the given context.

\section{Conclusion}

It is concluded that the prevalence of LBP among Bangladeshi physiotherapists was high. Lack of maintenance of correct posture, most frequent postures during practice, absence of lumber support on chair and feeling of mental stress on practice were the potential associated factors related to LBP. It is recommended to maintain selfprotecting techniques like maintain good postures, adequate lumber support, maintaining resting time between treatments, regular back strengthening exercise, etc., as well as proper rehabilitation.

\section{Acknowledgement}

The authors acknowledge all of the physiotherapists who participated in this study.

Conflict of interest: None declared.

\section{References}

1. Mehrdad R Md Mph, Shams-Hosseini NS Md, Aghdaei S Md, Yousefian M Md. Prevalence of low back pain in health care workers and comparison with other occupational categories in Iran: a systematic review. Iran J Med Sci 2016; 41(6):46778.

2. Jahan N, Das M, Mondal R, Paul S, Saha T, Akhtar $\mathrm{R}$ et el. Prevalence of musculoskeletal disorders among the Bangladeshi garments workers. SMU Medical Journal 2015; 2(1):102-13.

3. Jin K, Sorock GS, Courtney TK. Prevalence of low back pain in three occupational groups in Shanghai, Peoples Republic of China. J Safety Res 2004; 35(1):23-8.

4. Ory FG, Rahman FU, Katagade V, Shukla A, Burdorf A. Respiratory disorders, skin complaints, and lowback trouble among tannery workers in Kanpur, India. Am Ind Hyg Assoc J 2011; 58(10):740-6.

5. Almalki M, Alkhudhayri MH, Batarfi AA, Alrumaihi SK, Alshehri SH, Aleissa SI et al. Prevalence of low back pain among medical practitioners in tertiary care hospital in Riyadh. Saudi Journal of Sports Medicine 2016; 16(3):205-9.

6. Karahan A, Kav S, Abbasoglu A, Dogan N. Low back pain: prevalence and associated risk factors among hospital staff. J Adv Nurs 2009; 65(3):516-24

7. Alghadir A, Zafar H, lqbal ZA, Al-Eisa E. Workrelated low back pain among physical therapists in Riyadh, Saudi Arabia. Workplace Health Saf 2017; 65(8):337-45

8. Ahmed ET. Prevalence of work related low back pain in physical therapist professional from the city of Taif, KSA. International Journal of Physiotherapy 2016; 3(5):552-6.

9. Masoud FM. Prevalence and risk factors of low back pain among physical therapy professionals in Gaza Strip. [MSc thesis]. Gaza: The Islamic University of Gaza; 2008.

10. Alrowayeh HN, Alshatti TA, Aljadi SH, Fares $M$, Alshamire MM, Alwazan SS. Prevalence, characteristics, and impacts of work-related musculoskeletal disorders: a survey among physical therapists in the State of Kuwait. BMC Musculoskelet Disord 2010; 11:116.

11. Allegri M, Montella S, Salici F, Valente A, Marchesini $\mathrm{M}$, Compagnone $\mathrm{C}$ et al. Mechanisms of low back pain: a guide for diagnosis and therapy. [version2] F1000Res 2016; 5(F1000 Faculty Rev):1530.

12. Walker BF. The prevalence of low back pain: a systematic review of the literature from 1966 to 1998. J Spinal Disord 2000; 13(3):205-17.

13. Punnett L, Pruss-Utun A, Nelson DI, Fingerhut MA, Leigh J, Tak $S$ et al. Estimating the global burden of low back pain attributable to combined occupational exposures. Am J Ind Med 2005; 48(6):459-69.

14. Frymoyer JW, Cats-Baril WL. An overview of the incidences and costs of low back pain. Orthop Clin North Am 1991; 22(2):263-71.

15. Federspiel CF, Guy D, Kane D, Spengler D. Expenditures for nonspecific back injuries in the workplace. J Occup Med1989; 31(11):919-24.

16. Breivik H, Borchgrevink PC, Allen SM, Rosseland LA, Romundstad L, Hals EK et al. Assessment of Pain. Br J Anaesth 2008; 101(1):17-24.

17. World Health Organization. WHO Consultation on Obesity. Obesity: preventing and managing the global epidemic: report of a WHO consultation. Geneva, Switzerland: World Health Organization; 2000. Report No.: WHO technical report series; 894. Available from: http://www.who.int/iris/handle/10665/42330. [Accessed on April 28, 2018]. 